\title{
Acute Acalculous Cholecystitis Caused by Candida Albicans in a COVID-19 Patient: A Case Report
}

Haytham Wali ( $\sim$ haytham.a.wali@gmail.com )

Columbus Regional Healthcare System: Piedmont Healthcare Inc https://orcid.org/0000-0001-62793809

Deanne Tabb

Columbus Regional Healthcare System: Piedmont Healthcare Inc

Saeed A. Baloch

Columbus Regional Healthcare System: Piedmont Healthcare Inc

\section{Research Article}

Keywords: Acalculous Cholecystitis, COVID-19, Candida albicans

Posted Date: July 26th, 2021

DOl: https://doi.org/10.21203/rs.3.rs-319269/v1

License: (c) (i) This work is licensed under a Creative Commons Attribution 4.0 International License. Read Full License 


\section{Abstract}

\section{Background}

Acute acalculous cholecystitis is a necro-inflammatory disease of the gallbladder with multifactorial pathogenesis and is associated with high morbidity and mortality rates. Severe acute respiratory syndrome coronavirus 2 has been declared a pandemic that causes coronavirus disease-19 (COVID-19). Although many COVID-19 patients reported gastrointestinal symptoms such as anorexia, nausea, vomiting, and diarrhea, there was no evidence about the gallbladder and biliary tract involvement in the literature to date.

\section{Case Report}

A 71-year-old male was admitted to our facility and found to be positive for COVID-19. He received appropriate COVID-19 treatment with dexamethasone, remdesivir, and convalescent plasma. The patient continued to be lethargic, weak, and had elevated inflammatory markers. The arterial blood gas (ABG) panel showed metabolic acidosis with respiratory compensation, and the patient appeared to be overcompensating because of his hypoxia. Consequently, the patient was transferred to the intensive care unit (ICU) for intubation and mechanical ventilation. The total bilirubin started to increase over the following days and reached $8 \mathrm{mg} / \mathrm{dL}$. The ultrasound did not show cholelithiasis. The bile culture grew Candida albicans, and the patient was diagnosed with acalculous Candida cholecystitis. The patient had a significant deterioration in clinical status and expired after being transferred to comfort care.

\section{Conclusion}

Long-term complications of COVID-19 are still unknown. This case suggests the incidence of a fungal infection involving the gallbladder. Future research could help facilitate a better pathophysiological understanding of those complications.

\section{Introduction}

Acute acalculous cholecystitis (AAC) is a necro-inflammatory disease of the gallbladder with multifactorial pathogenesis [1]. It accounts for approximately $10 \%$ of all acute cholecystitis cases and is associated with high morbidity and mortality rates of around $30 \%$ [range, $10 \%-90 \%$ ] with early or late diagnosis, respectively. Severe acute respiratory syndrome coronavirus 2 (SARS-CoV-2) is a novel coronavirus that has not been previously identified in humans, and it is responsible for the coronavirus disease-19 (COVID-19) infection. The first case was identified in Wuhan, China, in December 2019, and it has spread to many countries around the world and was declared a global pandemic on March 11, 2020, by the World Health Organization (WHO) [2, 3]. Many COVID-19 patients reported gastrointestinal symptoms such as anorexia, nausea, vomiting, and diarrhea. However, to our knowledge, there has been no evidence of the gallbladder and biliary tract involvement with COVID-19. Therefore, we report a case of acute acalculous cholecystitis caused by Candida albicans in a patient with COVID-19 infection. 


\section{Case Report}

This was a 71-year-old male with a past medical history of benign prostatic hyperplasia (BPH), essential hypertension, and hyperlipidemia who was admitted to Piedmont Columbus Regional Midtown (PCRM) in Columbus, Georgia, United States, with a chief complaint of shortness of breath that started a week ago and has been worsening in the last 24 hours. The patient's weight was $80.3 \mathrm{~kg}$, and his body mass index (BMI) was $30.38 \mathrm{~kg} / \mathrm{m}^{2}$. His vital signs on admission were the following: temperature (oral), $36.7^{\circ} \mathrm{C}$ [98 ${ }^{\circ} \mathrm{F}$; blood pressure, 157/80 $\mathrm{mmHg}$; heart rate, 75 beats per minute; and respiratory rate, 22 breaths per minute. He had no history of tobacco, alcohol, or illicit drug use. A nasopharyngeal swab was obtained to test for SARS COV-2 using a reverse transcriptase polymerase chain reaction (RT-PCR) test (ID NOW ${ }^{\text {TM }}$ COVID-19, Abbott Diagnostics Scarborough, Inc., Scarborough, Maine, United States), and the patient was found to be positive for COVID-19. His SARS-CoV-2 immunoglobulin G ( $\mathrm{lgG}$ ) antibody was found to be negative. He required five liters of oxygen $\left(\mathrm{O}_{2}\right)$ through a nasal cannula (NC) on admission. The white blood cell (WBC) count on admission was $7.45 \times 10^{3} / \mu \mathrm{L}$ [normal range, $4-10.510^{3} / \mu \mathrm{L}$ ]. Chest X-ray showed bilateral infiltrates and small pleural effusion in the right lung. Infectious diseases service was consulted, and the patient was started on intravenous (IV) remdesivir (VEKLURY®, Gilead Sciences, Inc., Foster City, California, United States) [200 mg IV on day 1, followed by 100 mg IV every 24 hours for five days], dexamethasone [6 mg every 24 hours for ten days], and received a $250 \mathrm{~mL}$ of COVID-19 convalescent plasma under the Emergency Use Authorization (EUA) by the United States Food and Drug Administration (FDA). The oxygen requirement increased to $15 \mathrm{~L} / \mathrm{min}$ through a Venturi mask with a $50 \%$ fraction of inspired oxygen $\left(\mathrm{FiO}_{2}\right)$ and maintaining an $\mathrm{O}_{2}$ saturation at $93 \%$. With the oxygen saturation not improving, the patient changed to a high-flow nasal cannula (HFNC) with an oxygen flow rate of 40 $\mathrm{L} / \mathrm{min}$ and $95 \% \mathrm{FiO}_{2}$. The patient continued to be lethargic and weak, and had elevated inflammatory markers including lactate dehydrogenase (LDH) of $801 \mathrm{U} / \mathrm{L}$ [normal range, 120-230 U/L], ferritin of 616 $\mathrm{ng} / \mathrm{mL}$ [normal range, $40-300 \mathrm{ng} / \mathrm{mL}$ ], C-reactive protein (CRP) of $7.30 \mathrm{mg} / \mathrm{dL}$ [normal range, $\leq 1 \mathrm{mg} / \mathrm{dL}$ ], fibrinogen of $541 \mathrm{mg} / \mathrm{dL}$ [normal range, $200-430 \mathrm{mg} / \mathrm{dL}$ ], and D-dimer of $18.42 \mathrm{mcg} / \mathrm{mL}$ fibrinogen equivalent units (FEU) [normal range, $0.27-0.49 \mathrm{mcg} / \mathrm{dL}$ FEU]. The arterial blood gas (ABG) panel showed metabolic acidosis with respiratory compensation, and the patient appeared to be overcompensating due to hypoxia. Consequently, the patient was transferred to the intensive care unit (ICU) for intubation and mechanical ventilation.

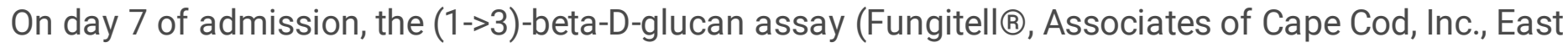
Falmouth, Massachusetts, United States) and Aspergillus Galactomannan Enzyme Immunoassay (EIA) (Platelia ${ }^{\mathrm{TM}}$, Bio-Rad Laboratories, Redmond, Washington, United States) were obtained and resulted negative. Seven days later, a repeat (1->3)-beta-D-glucan was $>500 \mathrm{pg} / \mathrm{mL}$, but the Aspergillus Galactomannan continued to be undetectable. Because the aspartate transaminase (AST) and alanine aminotransferase (ALT) were 243 and $395 \mathrm{U} / \mathrm{L}$, voriconazole could not be initiated, and the patient was started on amphotericin B lipid complex (ABELCET ${ }^{\circledR}$, Exelead, Inc., Indianapolis, Indiana) [300 mg IV every 24 hours] for possible COVID-associated pulmonary aspergillosis (CAPA). The endotracheal sputum culture obtained on day 13 of admission grew Candida albicans. 
On day 10 of admission, the patient was started on cefepime [ $2 \mathrm{~g}$ IV every 12 hours, the dose was renally adjusted for serum creatinine ( $\mathrm{SCr}$ ) of $2.13 \mathrm{mg} / \mathrm{dL}$ ] and linezolid [600 mg IV every 12 hours] for suspected hospital-acquired pneumonia (HAP). The following day, the liver function panel showed elevated aspartate transaminase (AST) and alanine aminotransferase (ALT) values of 856 and $910 \mathrm{U} / \mathrm{L}$, respectively, and linezolid was discontinued. A subsequent comprehensive metabolic panel (CMP) two days later showed the following: ALT of 7,761 U/L [normal range, 6-52 U/L], AST of 15,185 U/L [normal range, $\leq 42 \mathrm{U} / \mathrm{L}$ ], total bilirubin of $1.3 \mathrm{mg} / \mathrm{dL}$ [normal range, $\leq 1.2 \mathrm{mg} / \mathrm{dL}$ ], and alkaline phosphatase of $239 \mathrm{U} / \mathrm{L}$ [normal range, 35-125 U/L]. The total bilirubin continued to increase over the following days and reached $8 \mathrm{mg} / \mathrm{dL}$, which raised the suspicion of cholecystitis. The abdomen ultrasound showed a gallbladder wall that measures $0.3 \mathrm{~cm}$, no pericholecystic fluid collection, and a sludge within the gallbladder. Acalculous cholecystitis was suspected, and since the patient was a nonoperative candidate, interventional radiology (IR) was consulted for a percutaneous cholecystostomy tube placement. Twenty milliliters of thick bile were aspirated and sent to the microbiology lab for Gram stain and culture. The culture grew Candida albicans. Consequently, amphotericin B was changed to micafungin (MYCAMINE ${ }^{\circ}$, Astellas Pharma US, Inc., Northbrook, Illinois, United States) [100 mg IV every 24 hours].

Unfortunately, the patient had a significant deterioration in clinical status and developed septic shock requiring multiple vasopressors. Eventually, the patient's family opted for comfort care measures only.

\section{Discussion}

The etiology of AAC is multifactorial and likely results from bile stasis or ischemia (or both) [4]. Bile stasis can be caused by fasting, obstruction, postsurgical/procedural irritation, or total parenteral nutrition (TPN). The growth of organisms is ordinarily inhabited by the normal human bile salt concentration of $12 \%$ present in the gallbladder. However, the presence of cholestasis reduces this concentration, which may permit bacteria to proliferate in the biliary system $[5,6]$. Gastrointestinal symptoms have been reported with COVID-19. In a meta-analysis of 4243 patients with COVID-19, the prevalence of gastrointestinal symptoms was $17.6 \%$, including loss of appetite, nausea/vomiting, diarrhea, and abdominal pain [7]. Acalculous cholecystitis has been reported previously after an acute infection with Epstein Barr virus (EBV) [8]. Also, a case of acute acalculous cholecystitis has been reported in a COVID19 patient but with no pathogen identification [9]. Our case represents an acute acalculous cholecystitis possibly associated with COVID-19, and the causative organism was identified as Candida albicans.

Candida albicans in the gallbladder is thought to be a consequence of ascending migration of the organism within the biliary tract or hematogenous seeding during candidemia. In a retrospective chart review of 27 Patients with Candida spp isolated from the gallbladder or biliary tract, only 3 of 27 patients had candidemia, and 22 of 27 patients were colonized with Candida at other sites including sputum, urine, peritoneal fluid, catheter tip, and other sites [10]. An epidemiological study also found that patients presenting with severe forms of COVID-19, especially those who required mechanical ventilation, were at increased risk of developing candidemia [11]. It has been proposed that SARS-CoV-2 may increase intestinal permeability, potentially by causing damage to enterocytes and to the epithelial layer. This 
disruption of the intestinal mucosal barrier in COVID-19 patients could be an additional risk factor for candidemia by facilitating Candida species' translocation from the gut lumen to the bloodstream [12, 13, 14]. In our case, COVID-19 could have been associated with gut disruption resulting in Candida's translocation and, consequently, dissemination to the gallbladder. Although there was no fungal growth in the blood cultures, the possibility that our patient experienced candidemia could not be ruled out due to prior amphotericin B exposure.

Fungal organisms are an infrequent cause of gallbladder infections. Predisposing factors that could increase the risk of acute acalculous Candida cholecystitis include critical illness with prolonged hospitalization, malignancy, prolonged broad-spectrum antibiotic therapy, immunosuppression, treatment with histamine $\left(\mathrm{H}_{2}\right)$-receptor antagonists, gastric achlorhydria, diabetes mellitus, total parenteral nutrition, and intraabdominal surgery $[15,16]$. Our patient had multiple predisposing factors, including prolonged hospitalization, being on multiple broad-spectrum antibiotics, and receiving total parenteral nutrition.

Definitive treatment of AAC consists of cholecystectomy or, in poor surgical candidates, cholecystostomy. Alternatively, endoscopic retrograde cholangiopancreatography (ERCP) is an effective treatment option for patients who cannot tolerate surgery or cholecystostomy. In addition to drainage, patients on broadspectrum antimicrobials can be narrowed, based on the results of aspirated bile cultures [17]. In our case, cholecystectomy was not a feasible option considering the patient's COVID-19 infection and unstable condition. Therefore, cholecystostomy was performed through interventional radiology.

AAC can be associated with multiorgan dysfunction in critically ill patients $[18,19]$. Critically ill patients who are admitted to intensive care units have been found to have high mortality rates $(38 \%-80 \%)$, likely because of the disseminated Candida infection and candidemia $[16,18]$. In a retrospective, unmatched, observational cohort study of 24 patients who underwent an open cholecystectomy for AAC, the median total Sequential Organ Failure Assessment (SOFA) score three days before cholecystectomy was 7.5 and increased to $10.5(\mathrm{P}<0.0001)$ by the day of cholecystectomy, which indicated developing multiorgan dysfunction [19]. Our patient had a multiorgan failure, which could be the consequence of the combination of COVID-19 infection and AAC.

\section{Conclusion}

We report a case of AAC caused by Candida albicans in a patient with a COVID-19 infection. This case cannot establish a correlation between COVID-19 and AAC. However, considering that the long-term complications of COVID-19 are still unknown, future research could help facilitate a better pathophysiological understanding of those complications and provide a more precise explanation of the long-term effects of COVID-19.

\section{Declarations}

Funding 
The authors received no funding for this publication.

\section{Conflicts of Interest/Competing Interests}

All the authors report no potential conflicts of interest.

\section{Availability of Data and Material}

Not applicable.

\section{Code Availability}

Not applicable.

\section{Authors' Contributions}

The first draft of the manuscript was written by Haytham Wali, and all authors commented on previous versions of the manuscript. All authors read and approved the final manuscript.

\section{Ethics Approval}

The Columbus Regional Research Integrity Panel has confirmed that no ethical approval is required.

\section{Consent to Publish}

The relatives of the patient have consented to the submission of the case report to the journal.

\section{References}

1. Huffman JL, Schenker S. Acute acalculous cholecystitis: a review. Clin Gastroenterol Hepatol. 2010;8(1):15-22.

2. Saxena SK. Coronavirus Disease 2019 (COVID-19) Epidemiology, Pathogenesis, Diagnosis, and Therapeutics. Springer; 2020.

3. World Health Organization. (2020a) Coronavirus disease 2019 (COVID-19) situation report-51. World Health Organization. https://www.who.int/docs/defaultsource/coronaviruse/situationreports/20200311-sitrep-51-covid-19.pdf?sfvrsn1\%41ba62e57_10. Accessed December 16, 2020.

4. Knab LM, Boller A-M, Mahvi DM. Cholecystitis. Surg Clin North Am. 2014;94(2):455-70.

5. McChesney JA, Northup PG, Bickston SJ. Acute acalculous cholecystitis associated with systemic sepsis and visceral arterial hypoperfusion: a case series and review of pathophysiology. Dig Dis Sci. 2003;48(10):1960-7.

6. Júnior SA, de O, Lemos TEV, Junior AC de. M, et al. Acute acalculous cholecystitis in critically ill patients: risk factors, diagnosis and treatment strategies. JOP Journal of the Pancreas. 2016;17(6). 
7. Cheung KS, Hung IFN, Chan PPY, et al. Gastrointestinal manifestations of SARS-COV-2 infection and virus load in fecal samples from a Hong Kong cohort: systematic review and meta-analysis. Gastroenterology. 2020;159(1):81-95.

8. Rezkallah KN, Barakat K, Farrah A, et al. Acute Acalculous Cholecystitis due to primary acute EpsteinBarr virus infection treated with laparoscopic cholecystectomy; a case report. Annals of Medicine Surgery. 2018;35:189-91.

9. Mattone E, Sofia M, Schembari E, et al. Acute acalculous cholecystitis on a COVID-19 patient: a case report. Annals of Medicine Surgery. 2020;58:73-5.

10. Diebel LN, Raafat AM, Dulchavsky SA, Brown WJ. Gallbladder and biliary tract candidiasis. Surgery. 1996;120(4):760-5.

11. Nucci M, Barreiros G, Guimarães LF, Deriquehem VAS, Castiñeiras AC, Nouér SA. Increased incidence of candidemia in a tertiary care hospital with the COVID-19 pandemic. Mycoses. Published online December 4, 2020.

12. Nucci M, Anaissie E. Revisiting the source of candidemia: skin or gut? Clin Infect Dis. 2001;33(12):1959-67.

13. Sharma L, Riva A. Intestinal barrier function in health and disease-any role of SARS-COV-2? Microorganisms. 2020;8(11).

14. Uzzan M, Corcos O, Martin JC, Treton X, Bouhnik Y. Why is SARS-CoV-2 infection more severe in obese men? The gut lymphatics - Lung axis hypothesis. Med Hypotheses. 2020;144:110023.

15. Marsh PK, Tally FP, Kellum J, Callow A, Gorbach SL. Candida infections in surgical patients. Ann Surg. 1983;198(1):42-7.

16. Treinen C, Lomelin D, Krause C, Goede M, Oleynikov D. Acute acalculous cholecystitis in the critically ill: risk factors and surgical strategies. Langenbecks Arch Surg. 2015;400(4):421-7.

17. Owen CC, Jain R. Acute acalculous cholecystitis. Curr Treat Options Gastroenterol. 2005;8(2):99104.

18. Laurila J, Syrjälä H, Laurila PA, Saarnio J, Ala-Kokko TI. Acute acalculous cholecystitis in critically ill patients. Acta Anaesthesiol Scand. 2004;48(8):986-91.

19. Laurila J, Laurila PA, Saarnio J, Koivukangas V, Syrjälä H, Ala-Kokko TI. Organ system dysfunction following open cholecystectomy for acute acalculous cholecystitis in critically ill patients. Acta Anaesthesiol Scand. 2006;50(2):173-9.

20. Szvalb AD, Kontoyiannis DP. Acute acalculous cholecystitis due to Fusarium species and review of the literature on fungal cholecystitis. Mycoses. 2019;62(9):847-53. 